\title{
Wernicke Encephalopathy Due to Prolonged Total Parenteral Nutrition in A Child with Signet Ring Cell Gastric Carcinoma
}

\begin{tabular}{|c|c|c|}
\hline Author(s) & \multicolumn{2}{|c|}{ (D)Buket Kara', (D)Ayşe Kartal², (D) Mehmet Öztürk³, (D)Yavuz Köksal¹ } \\
\hline Affiliation(s) & $\begin{array}{l}\text { 'Selcuk University, Faculty of Medicine, D } \\
{ }^{2} \text { Selcuk University, Faculty of Medicine, D } \\
{ }^{3} \text { Selcuk University, Faculty of Medicine, D }\end{array}$ & $\begin{array}{l}\text { t of Pediatric Hematology and Oncology, Konya, Turkey } \\
\text { t of Pediatric Neurology, Konya, Turkey } \\
\text { t of Radiology, Konya, Turkey }\end{array}$ \\
\hline $\begin{array}{c}\text { Article } \\
\text { Information }\end{array}$ & $\begin{array}{l}\text { Article Type: Case Report } \\
\text { Article Group: Pediatric Hematology-Oncology }\end{array}$ & $\begin{array}{l}\text { Received: } 28.04 .2020 \\
\text { Accepted: } 10.06 .2020 \\
\text { Available Online: } 31.07 .2020\end{array}$ \\
\hline
\end{tabular}

\section{Abstract}

Signet ring cell gastric carcinoma is extremely rare during childhood. One of the most important problems in these patients is nutritional difficulty and impairment, and these patients are often supported by total parenteral nutrition. Herein, the authors report a case of Wernicke encephalopathy due to prolonged total parenteral nutrition in a 13-year-old girl with diffuse gastric cancer with signet ring cell.

Keywords: Gastric carcinoma, signet ring cell, Wernicke encephalopathy, total parenteral nutrition

\section{Introduction}

Wernicke's encephalopathy caused by thiamin deficiency is seen frequently absorption problems such as malnutrition and hyperemesis, increased metabolism such as sepsis and malignancy, and increased carbohydrate intake such as administration of intravenous dextrose. Its clinical manifestations are altered mental state including confusion and encephalopathy, ocular abnormalities including nystagmus and ophtalmoplegia, and cerebellar dysfunction including gait disturbance and ataxia. ${ }^{1-3}$ The disorder results from a defi ciency invitamin B1 (thiamine), which in its biologically active form, thiamine pyrophosphate, is an essential coenzyme in several biochemical pathways in the brain. It has been reported in different childhood cancers including leukemia, central nervous system, neuroblastoma and osteosarcoma. ${ }^{4-15}$

Childhood gastric tumors are very rare and a significant proportion of them are lymphoma and sarcomas. Presenting symptoms are pain located at epigastric region, feeling of fullness, belching, nausea, vomiting, weight loss, and 
loss of appetite. ${ }^{16,17}$ The most important problems in these patients are nutritional difficulty and impairment at follow-up. Generally, this problem is solved by total parenteral nutrition (TPN). Herein, the authors report a case of Wernicke encephalopathy due to prolonged total parenteral nutrition in a 13-year-old girl with diffuse gastric cancer with signet ring cell.

\section{Case}

A 13-year-old girl admitted in a local hospital presenting with complaints of dysphagia for five years, odynophagia for 2 years, weight loss (>10 kg over 2 years), regurgitation for 6 months, chest pain and heartburn. On barium swallow, the esophagus was dilated and contrast material passed slowly into stomach as the lower esophageal sphincter was opening intermittently and the distal esophagus was narrow and was described as resembling a bird's beak. Endoscopic examination and biopsy ruled out cancer of gastroesophageal junction or fundus. The patient was referred to another center with initial diagnosis for achalasia. Laparoscopic cardiomyotomy was planned for achalasia. However, gastric linitis plastica, peritoneal carcinomatosis and ascites were detected during operation. So, the patient was considered as unresectable gastric carcinoma. Only biopsy could be performed. Signet ring cell gastric carcinoma was diagnosed. After that, she referred to our hospital for chemotherapy.

She was presented to our clinic with complaints of severe abdominal and back pain, abdominal distension, nausea and vomiting and weight loss. Also, she could not eat or drink anything. Physical examination revealed cachexia, pale, abdominal discomfort and abdominal distension.
The patient was started on systemic 5-fluorouracil and oxaliplatin (FOLFOX)[18]. Also, TPN without multivitamins was initiated. There was a decrease in the pain and distention of the patient in the days following chemotherapy. However, there was no significant improvement in oral intake and so, TPN was continued. On the 40th day of TPN, complaints of hallucination and confusion had begun. Physical examination revealed ataxia, ophthalmoplegia, nistagmus, areflexia and encephalopathy. Biochemistry was normal. On magnetic resonance imaging, the axial fluid attenuated inversion recovery weighted imaging showed that abnormal high signal intensity in both periventricular areas, medial and dorsomedial thalamus and caudate nucleus, suggesting the diagnosis of Wernicke encephalopathy (Figure 1a and Figure 1b). The patient was instituted thiamine $500 \mathrm{mg}$ intravenously once a day for Wernicke Encephalopathy. At the third day of the thiamine, the symptoms and findings improved. However, the patient died of primary disease.

\section{Discussion}

Wernicke's encephalopathy, an acute and neuropsychiatric syndrome, is characterized by nistagmus and ophtalmoplegia, mental-status changes, and unsteadiness of stance and gait. 1,3,19 However, these findings are only seen in a small proportion of patients. Clinical statuses related to Wernicke's encephalopathy are staple diet of polished rice, chronic alcohol abuse and malnutrition, gastrointestinal surgical procedures, recurrent vomiting or chronic diarrhea, cancer and chemotherapeutic treatments, systemic diseases, magnesium depletion, use of chemical compounds and drugs, and unbalanced nutrition., 3

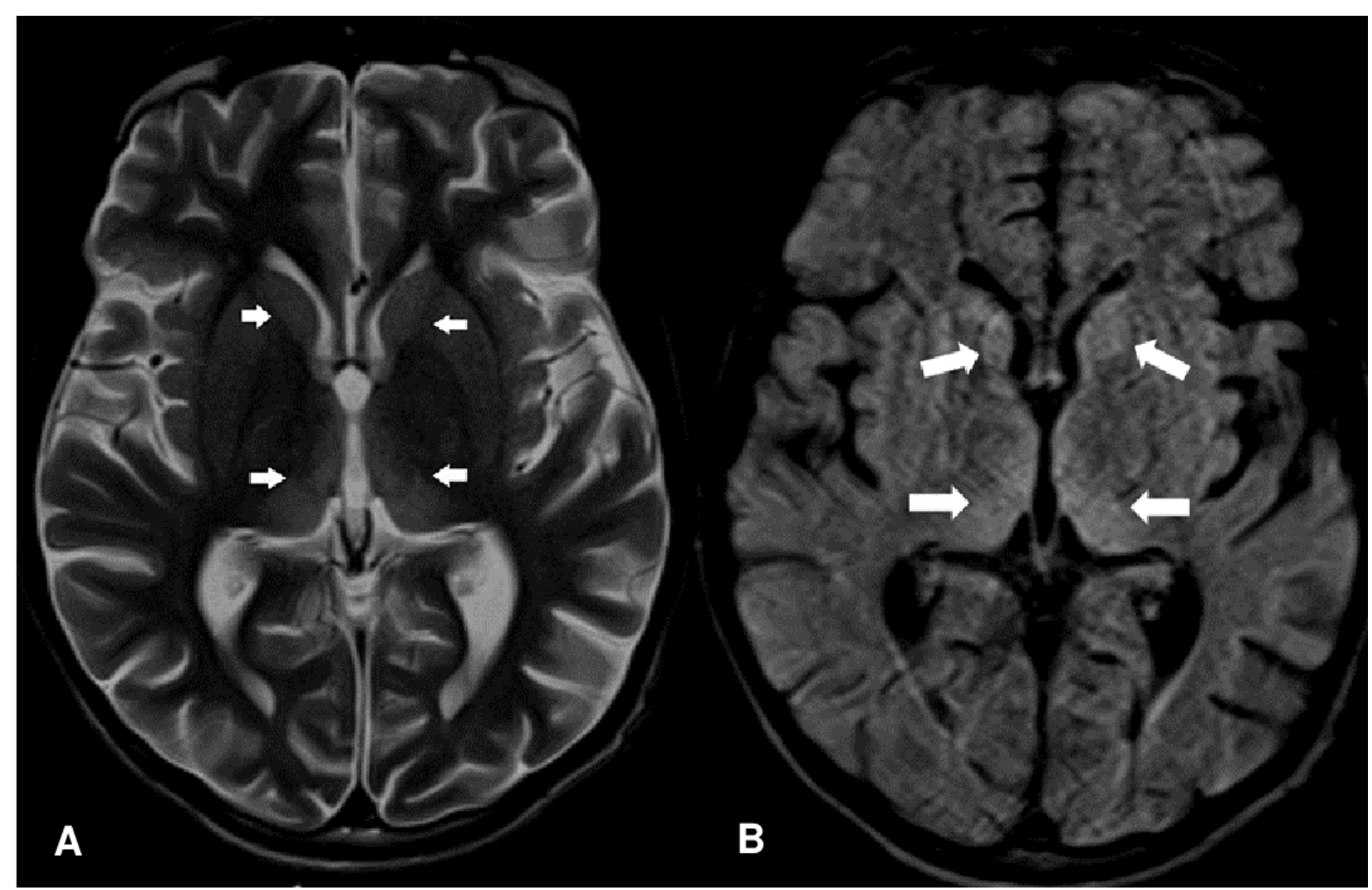

Figure 1. (a) The axial T2 and (b) FLAIR weighted imaging showed that abnormal high signal intensity in bilateral and symmetrical hyperintense lesions in pulvinar and dorsomedial thalami 
The most common known symptoms and signs of the Wernicke encephalopathy are alteration of sensorium, oculomotor dysfunction with ophtalmoplegia and gait ataxia. However, all of these well-known clinical features cannot be seen completely in all of the patients with Wernicke encephalopathy. Also, some uncommon and non-specific symptoms and sings including hypotension, tachycardia, hypothermia, bilateral visual disturbances, papilledema, sluggish pupillary reaction, anisocoria, mydriasis, hypotonia, absence of deep tendon reflexes, tremor, seizures including status epilepticus, hearing loss, hallucinations and behavioral disturbances; $n$ later periods, hyperthermia, hypertonia, paresis, dyskinesia, comaand death can be seen ${ }^{1-3}$ In our patient, hallucination, confusion, ataxia, ophthalmoplegia, nistagmus, areflexia and encephalopathy were determined.

In addition to clinical features, magnetic resonance imaging is also helpful in the diagnosis of Wernicke encephalopathy. The most common magnetic resonance imaging findings of Wernicke encephalopathy are an increased T2 signal, bilaterally symmetrical, in the paraventricular regions of the thalamus, the hypothalamus, mamillary bodies, the periaqueductal region, the floor of the fourth ventricle and midline cerebellum. ${ }^{2,3,9}$ In our patient, magnetic resonance imaging show that the axial fluid attenuated inversion recovery weighted imaging showed that abnormal high signal intensity in both bilateral thalamus and caudate nucleus.

Up to now, Wernicke encephalopathy has been reported in some childhood cancers including leukemias (acute or chronic), non-Hodgkin lymphoma, central nervous system tumors (primitive neuroectodermal tumor, medullolastoma, germ cell tumor and pontine glioma), osteosarcoma, and rhabdomyosarcoma. Wernicke's encephalopathy developing in children with cancer in the English literature which full text can be reached are summarized in Table 1. Factors that facilitate the development of Wernicke's encephalopathy in children with cancer are rapidly proliferating and growing cancer cells, increased catabolism, some chemotherapeutic agents interacting with thiamine, vomiting, poor intake, and prolonged TPN. . $^{4-17}$

In conclusion, Wernicke encephalopathy should be kept in mind in pediatric patients with cancer especially with rapidly proliferating and growing cancer cells such as leukemia, non-Hodgkin lymphoma and some central nervous system tumors and who need to be fed with prolonged TPN.

Informed Consent: Written informed consent was obtained from patients who participated in this study.

Peer-review: Externally peer-reviewed.

Author Contributions: Conception; Buket Kara, Ayşe Kartal, Mehmet Öztürk, Yavuz Köksal Design; Buket Kara, Yavuz Köksal, Supervision; Yavuz Köksal, Data Collection and/or Processing; Buket Kara, Ayşe Kartal, Mehmet Öztürk, Yavuz Köksal, Literature Review; Buket Kara, Yavuz Köksal

Conflict of Interest: The authors have no conflict of interest to declare.

Financial Disclosure: The authors declared that this study has received no financial support

\begin{tabular}{|c|c|c|c|c|c|c|c|c|}
\hline \multirow[b]{2}{*}{ No } & \multirow{2}{*}{$\begin{array}{l}\text { Age I } \\
\text { Gender }\end{array}$} & \multirow[b]{2}{*}{ Diagnosis } & \multicolumn{4}{|c|}{ Risk Factors } & \multirow[b]{2}{*}{ Treatment } & \multirow[b]{2}{*}{ Reference } \\
\hline & & & Vomiting & $\begin{array}{l}\text { TPN (days) with / } \\
\text { without MVs }\end{array}$ & $\begin{array}{l}\text { Poor } \\
\text { intake }\end{array}$ & SCT & & \\
\hline OP & $13 / \mathrm{F}$ & Gastric carcinoma (signet ring cell) & + & $+(40)$, w/o MVs & + & - & Thiamine & \\
\hline 1 & $12 / \mathrm{M}$ & ALL (with ASD) & + & - & + & - & Thiamine & 4 \\
\hline 2 & $13 / F$ & ALL & + & $+(8)$, w/o MVs & + & - & Thiamine & 5 \\
\hline 3 & $10 / M$ & ALL (Down syndrome) & + & $+(5)$, w/o MVs & + & - & Thiamine & 6 \\
\hline 4 & $5 / F$ & Neuroblastoma & - & + (?), with MVs & + & + & Thiamine & 7 \\
\hline 5 & $6 / \mathrm{M}$ & Pontine glioma & - & - & - & - & Thiamine & 8 \\
\hline 6 & $12 / \mathrm{M}$ & CNS PNET & - & $+(?)$, unknown & + & + & Thiamine & 8 \\
\hline 7 & $5 / F$ & Medulloblastoma & + & $+(?)$, w/o MVs & + & - & Thiamine & 9 \\
\hline 8 & 9/F & Osteosarcoma & - & - & + & - & Thiamine & 9 \\
\hline 9 & $19 / F$ & AML & + & + (60), w/o MVs & + & - & Thiamine & 9 \\
\hline 10 & $4 / F$ & Rhabdomyosarcoma & - & + (14), with MVs & + & - & Thiamine & 9 \\
\hline 11 & $6 / M$ & Medulloblastoma & + & - & + & + & Thiamine & 9 \\
\hline 12 & $10 / F$ & Osteosarcoma & + & - & + & - & Thiamine & 10 \\
\hline 13 & $6 / M$ & Germ cell tumor & - & $+(?)$, unknown & - & - & Thiamine & 10 \\
\hline 14 & $12 / F$ & AML & - & $+(?)$, unknown & - & - & Thiamine & 10 \\
\hline 15 & $12 / M$ & AML (CNS positive) & + & $+(30), w / o M V s$ & + & - & Thiamine & 11 \\
\hline 16 & $16 / M$ & ALL (panceatitis) & + & + (14), w/o MVs & + & - & Thiamine & 12 \\
\hline 17 & $12 / M$ & AMLL & + & + (?), w/o MVs & + & - & Thiamine & 13 \\
\hline 18 & $17 / F$ & Osteosarcoma & + & $+(?)$, unknown & - & - & $?$ & 14 \\
\hline 19 & $9 / M$ & ALL & - & - & - & - & Thiamine & 15 \\
\hline
\end{tabular}

OP: Our patient, F: Female, M: Male, TPN: total parenteral nutrition, w/o: with out, MVs: multivitamins, ALL: acute lymphoblastic leukemia, ASD: autism spectrum disorder SCT: Stem Cell Transplant, CNS PNET: Central nervous system primitive neuroectodermal tumor, AML: acute myeloid leukemia, AMLL: acute mixed lineage leukemia 


\section{References}

1. Gregory S, Day C, del Campo M. Wernicke encephalopathy: a medical emergency. CMAJ. 2014; 186: E295. [CrossRef]

2. Lallas M, Desai J. Wernicke encephalopathy in children and adolescents. World J Pediatr. 2014; 10: 293-8. [CrossRef]

3. Sechi G, Serra A. Wernicke's encephalopathy: new clinica settings and recent advances in diagnosis and management. Lancet Neurol. 2007; 6: 442-55. [CrossRef]

4. Cefalo MG, De loris MA, Cacchione A, et al. Wernicke encephalopathy in pediatric neuro-oncology: presentation of 2 cases and review of literature. J Child Neurol. 2014; 29: NP181-5. [CrossRef]

5. Darlington WS, Pinto N, Hecktman HM, et al. Stem cell transplantassociated Wernicke encephalopathy in a patient with highrisk neuroblastoma. Pediatr Blood Cancer. 2015; 62: 2232-4. [CrossRef]

6. Kálmánchey R, Koós R, Majtényi Ketal. Wernicke-encephalopathy in children with cancer. Med Pediatr Oncol. 1994; 22: 133-6. [CrossRef]

7. Kızılocak H, Özdemir G, Dikme G, et al. Wernicke's encephalopathy in a child with acute lymphoblastic leukemia. Turk $J$ Haematol 2017; 34: 99-100. [CrossRef]

8. La Spina M, Catania R, Lo Nigro L, et al. Neurological complications during treatment of childhood cancer: mind Wernicke encephalopathy. Pediatr Hematol Oncol. 2010 ; 27: 3203. [CrossRef]

9. Lim Y-J, Kim H-J, Lee Y-J, et al. Clinical features of encephalopathy in children with cancer requiring cranial magnetic resonance imaging. Pediatr Neurol. 2011; 44: 433-8. [CrossRef]

10. Miyajima Y, Fukuda M, Kojima S, et al. Wernicke's encephalopathy in a child with acute lymphoblastic leukemia. $A m$ J Pediatr Hematol Oncol. 1993; 15: 331-4. [CrossRef]
11. Muwakkit S, Al-Aridi C, Saab R, et al. Wernicke's encephalopathy during total parenteral nutrition in a child with acute lymphoblastic leukemia and acute pancreatitis. Neuropediatrics. 2009; 40: 249251. [CrossRef]

12. Onodera $\mathrm{N}$, Nakahata $\mathrm{T}$, Tanaka $\mathrm{H}$, et al. Successful treatment of Wernicke's encephalopathy in a boy with acute mixed lineage leukemia. Acta Paediatr Jpn.1998; 40: 271-274. [CrossRef]

13. Perko R, Harreld JH, Helton $\mathrm{KJ}$, et al. What goes around comes around? Wernicke encephalopathy and the nationwide shortage of intravenous multivitamins revisited. J Clin Oncol. 2012; 30: e318-e320. [CrossRef]

14. Yıldırım AT, Bilgili G, Akman B, et al. Wernicke's encephalopathy in a child with Down syndrome, undergoing treatment for acute lymphoblastic leukemia. Pediatr Int. 2016; 58: 757-759. [CrossRef]

15. Zensho $K$, Ishida $H$, Nagai $H$, et al. A Wernicke's encephalopathy in a child with autism during chemotherapy for T-cell acute leukemia. Pediatr Int. 2018; 60: 757-758. [CrossRef]

16. Aydoğan A, Corapçioğlu F, Elemen EL, et al. A case report: gastric adenocarcinoma in childhood. Turk $J$ Pediatr. 2009; 51: 489-492. [CrossRef]

17. Patiroglu $T$, Eke Gungor H, Arslan D, et al. Gastric signet ring carcinoma in a patient with ataxia-telangiectasia: a case report and review of the literature. J Pediatr Hematol Oncol. 2013; 35: e341-3. [CrossRef]

18. Peixoto RDA, de Sousa TT, Silva PAIA, et al. Complete Response for More than 4 Years following Neoadjuvant FOLFOX and Cytoreductive Surgery with Hyperthermic Intraperitoneal Chemotherapy for a Patient with Advanced Gastric Cancer with Extensive Peritoneal Carcinomatosis. Case Rep Oncol. 2018; 11: 305 [CrossRef]

19. Tozzo P, Caenazzo L, Rodriguez D, et al. Delayed diagnosis of Wernicke encephalopathy with irreversible neural damage after subtotal gastrectomy for gastric cancer: A case of medical liability? Int J Surg Case Rep. 2017; 30: 76-80. [CrossRef] 